\title{
Estrategia de motivación para estudiantes de primer año de Medicina, Universidad San Sebastián, Concepción, Chile
}

\author{
P. Jorquera-Aguayo, G. Acuña-Gamé, M. Ramos-Jiménez
}

Introducción. En el marco de un nuevo modelo educativo formativo, la Universidad San Sebastián apunta al desarrollo de estrategias pedagógicas que sitúan al estudiante en el centro de las acciones. Es así como surge la necesidad de incrementar la motivación en los jóvenes que ingresan a la carrera de medicina, profesión desde siempre ligada a los valores sociales y el altruismo. Este trabajo explora la relevancia del contacto temprano con el paciente y el hospital como fuentes de motivación en primer año. Sujetos y métodos. Todos los estudiantes de primer año de medicina $(n=115)$ fueron invitados a visitar voluntariamente un hospital. Allí, los estudiantes recorrieron el establecimiento y sostuvieron una conversación libre con un paciente. Las opiniones se recogieron a través de un escrito libre. Resultados. Se inscribieron 95 estudiantes, de los cuales 68 concurrieron a la visita. Al consultar sobre la vivencia con el paciente, los estudiantes se refirieron positivamente a ésta. La ansiedad al inicio de la conversación fue uno de los aspectos más mencionados, al igual que la importancia de conocer el futuro lugar de trabajo. Conclusiones. La experiencia evidenció un alto interés en participar. Asimismo reveló elementos de la vida afectiva de los estudiantes, pilar fundamental de la educación médica. Finalmente, se aconseja la temprana relación con el paciente y con el hospital como agentes motivacionales en primer año. Se sugiere incorporar tareas y complementar la evaluación con herramientas que permitan obtener información objetiva sobre los aprendizajes adquiridos.

Palabras clave. Educación médica. Motivación. Relación estudiante-paciente.

\section{Motivation strategy for first year medical students, Universidad San Sebastián, Concepción, Chile}

Introduction. In the context of a new educational model of training, Universidad San Sebastián aims to develop teach- ing strategies that place the student at the center of action. Thus, it arises the need to increase motivation in young people entering the medical program, a profession that always has been linked to social values and altruism. This paper explores the relevance of early contact with the patient and the hospital as sources of motivation in the first year. Subjects and methods. All first year medical students $(\mathrm{n}=115)$ were invited to visit a hospital voluntarily. There, the students visited the facilities and held a free conversation with a patient. The views were collected through a free writing. Results. 95 students were enrolled, of whom 68 did the visit. When consulted about the patient experience, students spoke positively of it. The anxiety at the beginning of the conversation was one of the most mentioned aspects as it was the importance of knowing the future workplace. Conclusions. The experience showed a high level of interest in participating. Also, it revealed elements of the student's emotional life, basis of major importance for the medical education. Finally, it is recommend the early relationship with the patient and the hospital as motivational agents in the first year. It is suggested the incorporation of tasks and complementing of the evaluation with tools that allow obtaining objective information on apprenticeship.

Key words. Medical education. Motivation. Student-patient relationship.

\section{Introducción}

La Universidad San Sebastián impulsa desde el año 2008 un nuevo modelo educativo formativo. Mediante el diseño de un currículo centrado en el aprendizaje y modelos pedagógicos integrados, se busca formar estudiantes con competencias acordes con el escenario laboral actual. En este contexto, se crean las Comunidades Académicas,
Universidad San Sebastián. Concepción, Chile.

Correspondencia Profa. Paola Jorquera Aguayo. Escuela de Medicina. Universidad San Sebastián. General Cruz, 1577. Concepción, Chile.

E-mail

pjorquera@uss.cl

Agradecimientos Esta experiencia no se hubiera podido realizar sin la generosa participación del personal de los Hospitales de Lota y Coronel. Deseamos además extender nuestro reconocimiento a todos los médicos que participaron como tutores, en especial la Dra. C. Muñoz y el Dr.

J. Martínez.

Dedicado a la memoria de la Dra. Silvia Fodich Andrade. 
grupos conformados por todos los profesores que imparten asignaturas en un mismo año académico. Es así como la Comunidad Académica de primer año de medicina agrupa los profesores de biología, bioquímica, biomatemáticas, anatomía, fundamentos de enfermería, física médica, introducción a la medicina y aprendizaje basado en problemas. Su principal función es dar cumplimiento a los objetivos trazados en los programas de las distintas asignaturas, mediante la unificación de criterios y la elaboración de estrategias pedagógicas adaptadas a las diversas características de los estudiantes. Con el fin de facilitar esta labor, se crea el Sistema de Apreciación del Desarrollo (SAD), instrumento aplicado a los estudiantes de primer año de todas las carreras y que mide cuatro ítems: motivaciones y expectativas frente a la carrera, interrogantes vocacionales en torno a la carrera, habilidades cognitivas y capacidad de autoevaluación. Datos provenientes del SAD 2008 muestran que las principales motivaciones de los estudiantes que ingresan en medicina son poder ayudar a los demás $(85 \%)$, alcanzar dominio práctico $(53 \%)$ y poder contar con las herramientas que permitan contribuir al desarrollo del país (51\%). En cuanto a los interrogantes en torno a la elección de la carrera de medicina, un $34 \%$ de los estudiantes se pregunta si cuenta con la preparación suficiente para tener un buen desempeño durante la carrera, un $33 \%$ si el ejercicio profesional futuro afectará su vida personal, un $10 \%$ si a través del quehacer médico podrá contribuir al mejoramiento de las condiciones de vida de la población, y un $9 \%$ si esta carrera responde a su auténtica vocación [1]. La evidencia muestra que si bien los estudiantes pueden llegar a la universidad con niveles muy altos de motivación, es muy frecuente que ésta decaiga con el paso de los años [2]. En este sentido, una de las funciones principales de la Comunidades Académicas debe ser asegurarse de que los estudiantes tengan y mantengan la motivación suficiente a la hora de asumir los desafíos propios del aprendizaje.

Hoy día, la bibliografía es clara en señalar la importancia de atender no sólo a los componentes cognitivos implicados en el aprendizaje, sino también a los de carácter afectivo o motivacionales $[3,4]$. Refiriéndose a esto, Míguez [2] plantea de manera contundente que los estudiantes motivados aprenden con mayor rapidez y más eficazmente que los estudiantes que no están motivados. Del mismo modo, el autor señala que al tener expecta- tivas claras y positivas, resultan más gratificantes las tareas y actividades que se deben emprender. Mc Robbie y Tobin [5] argumentan también que cuando las tareas académicas se valoran como interesantes, importantes y útiles, los estudiantes pueden estar más dispuestos a aprender.

Otro aspecto vinculado a la motivación es el rendimiento académico. Al respecto, Durán [6] ha demostrado que un $40 \%$ del éxito universitario se debe a la motivación de los estudiantes, siendo el nivel motivacional alcanzado en primer año de estudios un determinante clave de todo el desarrollo de la carrera. Una investigación realizada por la Universidad de Chile [7] confirma esta asociación y agrega que el rendimiento académico puede verse influido además por problemas vocacionales, debilidades académicas previas, inadecuadas metodologías de enseñanza y aprendizaje e insatisfacción con la carrera. Por ello, no es de extrañar que los autores promuevan la incorporación de estrategias que retroalimenten tempranamente a los estudiantes para identificar sus debilidades y corregirlas a tiempo. Otro aspecto destacado por este estudio es la manera en que los estudiantes ven al docente. En efecto, si a los estudiantes no les gusta el profesor, la motivación será más baja, pues no querrán asistir a clases o a las actividades prácticas. Por lo mismo, el profesor tiene que ser amable y accesible, y no una figura dominante que genera rechazo en los estudiantes. Conforme a lo anterior, Huertas [3] ofrece algunas pistas para fomentar la acción motivada en los estudiantes y, con ello, sus ganas de aprender: carácter activo y voluntario de las actividades, persistencia en el tiempo, vinculación con las necesidades adaptativas, orientación hacia metas y consideración de los componentes afectivos y emocionales de quienes participan.

En este trabajo se examina la relevancia del contacto temprano con el paciente y la institución hospitalaria como fuentes de motivación para estudiantes de primer año de medicina.

\section{Sujetos y métodos}

En el marco de una estrategia motivacional diseñada por la Comunidad Académica, se invitó a todos los estudiantes de primer año de medicina $(n=115)$ a visitar por primera vez un hospital. La inscripción fue voluntaria y para esto se solici- 
tó a los estudiantes que conformaran libremente grupos de seis personas. Cada grupo asistió un día, sábado de 09:00 a 12:30 h, al Hospital de Lota o de Coronel, establecimientos de mediana complejidad ubicados a $43 \mathrm{~km}$ de la ciudad de Concepción. Cada grupo estuvo a cargo de tres médicos tutores, quienes guiaron a los estudiantes durante todo el transcurso de la visita. Las actividades se desarrollaron durante los meses de octubre y noviembre del segundo semestre académico del año 2008.

Una vez en el hospital, los estudiantes recorrieron el establecimiento acompañados de sus tutores, quienes relataron aspectos generales sobre su funcionamiento y organización. Seguidamente, concurrieron al servicio clínico de medicina, donde los tutores solicitaron el consentimiento informado de los pacientes para sostener una conversación con los estudiantes. Una vez obtenido éste, se asignó un estudiante a cada paciente, con el que pudo comunicarse libre y espontáneamente durante 45 minutos. Cabe mencionar que esta interacción no se basó en ningún tipo de preparación o indicación por parte de los tutores. Una vez finalizada la actividad, se consultó a los estudiantes respecto de su vivencia. Las opiniones se recogieron mediante un escrito libre organizado en torno a cuatro preguntas abiertas de dos páginas de extensión. Las preguntas fueron:

- ¿Cómo fue tu encuentro con el paciente?

- ¿Qué es lo que más te gustó de la visita?

- ¿Qué es lo que menos te gustó de la visita?

- ¿Que cambiarías de la visita?

El estudio de la información se realizó mediante análisis de contenidos.

\section{Resultados}

De 115 estudiantes de primer año de medicina, se inscribieron 95 (82\%). De éstos, sólo 68 concurrieron el día asignado para la visita (59\%). Al consultar sobre la vivencia con el paciente, los atributos 'conmovedor', 'reconfortante' y 'enriquecedor' fueron las respuestas más mencionadas entre los estudiantes. La frase 'fue un grato momento hablar, reír y comentar cosas que teníamos en común, olvidarme por un instante de su condición de enfermo... lo refleja bien. Otro pun- to destacado fue la importancia de conocer las circunstancias familiares y sociales del paciente. Seguidamente, identificaron sus emociones al enfrentarse por primera vez a un paciente. La anotación 'al principio estaba ansioso, pero después me sentí tranquilo’ fue la más recurrente. Además, los estudiantes apreciaron la posibilidad de conocer el significado de la hospitalización a partir del propio paciente. En este sentido, algunos expresaron: 'es importante conocer el punto de vista del paciente porque son cosas que no están en los libros'. En cuanto a la evaluación de la experiencia, los aspectos mejor evaluados por los estudiantes fueron visitar el futuro lugar de trabajo, sostener el primer contacto con un paciente y el hospital, y la buena disposición de los médicos tutores para responder a sus preguntas. Respecto de lo negativo, surgió la disconformidad con la corta duración de la actividad y un sentimiento de mal aprovechamiento del encuentro con el paciente, en el sentido de no haber realizado técnicas básicas de valoración, como la medición de signos vitales. Finalmente, los estudiantes sugirieron incluir este tipo de experiencia al inicio del primer semestre académico, que sea de carácter obligatorio y que las visitas se efectúen de manera continuada, es decir, todas las semanas.

\section{Discusión}

Los estudiantes respondieron positivamente a la invitación, lo que se reflejó en el alto porcentaje de inscritos (82\%). Esto podría explicarse por varios factores, entre los cuales se mezclan la curiosidad ante lo desconocido [4], el carácter voluntario [3] y la vinculación con las motivaciones [2] detectadas por el SAD. Sin embargo, al comparar el número de inscritos $(n=95)$ con el número de asistentes a las visitas $(n=68)$, se constató una baja considerable. Por una parte, la no concurrencia de 27 estudiantes podría deberse al período de pruebas de asignaturas de primer año coincidente con algunas de las fechas de las visitas. Por otra parte, podría explicarse por una insuficiente valoración de la actividad [5], aspecto menos probable si se presta atención al porcentaje de inscritos. Se advierte así la necesidad de investigar a fondo los factores que intervienen tanto en la inscripción como en la inasistencia de los estudiantes, todo ello con el fin de mejorar la efectividad de las 
estrategias educativas y alcanzar una mayor participación en las actividades propuestas. Ahora, si bien un grupo considerable de estudiantes inscritos no se presentó a la actividad, un 59\% sí lo hizo. Esta observación es de gran relevancia si se considera, en primer lugar, que la visita se efectuó un día habitualmente de descanso para los estudiantes de primer año. En segundo lugar, que varios estudiantes residen lejos de Concepción, por lo que el sábado constituye un día para viajar a visitar a la familia. Considerando estos dos aspectos, podríamos estar ante la presencia de un grupo de estudiantes altamente motivados y con un mayor compromiso hacia su propio aprendizaje. Podrían ser éstas dos de las principales características de quienes eligen estudiar medicina, más allá del altruismo y orientación hacia los valores sociales. En este sentido, Míguez [2] señala que la motivación y las estrategias que se ponen en juego en contextos favorables son esencialmente diferentes a aquellas que se manifiestan cuando se está a disgusto y obligado, lo que influye directamente en la calidad del aprendizaje. Por esto mismo, es importante motivar a quien quiere aprender.

El encuentro con el paciente reveló además elementos de la vida afectiva de los estudiantes. En este sentido, se debe tener muy presente que se trató de un primer contacto con una persona hospitalizada. Esta vivencia, de gran trascendencia, podría tener dos repercusiones en la vida de un joven universitario: la reafirmación de la vocación o bien la reorientación de un proyecto de estudios. Al respecto, podemos decir con certeza que es responsabilidad de las universidades generar estrategias que retroalimenten tempranamente a los estudiantes, con el fin de resolver dudas vocacionales al inicio y no elevar los niveles de incertidumbre conforme avanza la carrera. Estos factores adquieren mayor importancia en carreras de alta exigencia y de larga duración, como es el caso de medicina.

Por último, esta experiencia muestra la relevancia de incorporar la temprana relación con el paciente y con el hospital como agentes motivacionales en primer año de medicina. Esto se desprende de los escritos, donde los estudiantes sugieren, entre otros, incorporar el hospital y el contacto con los pacientes como ambientes educativos desde el primer semestre de estudios. Ante este panorama, podría aprovecharse mejor esta experiencia, agregando tareas que aporten beneficios al aprendizaje de las diversas asignaturas de primer año. Asimismo, sería pertinente complementar la evaluación subjetiva con herramientas que permitan obtener información de carácter objetivo sobre los aprendizajes, como rúbricas y listas de cotejo [8]. Sólo de esta manera se logrará retroalimentar nuestra práctica docente generando la información suficiente para la toma de decisiones.

\section{Bibliografía}

1. Universidad San Sebastián. Sistema de Apreciación del Desarrollo (SAD): resultados carrera de Medicina. Informe del Centro de Innovación Curricular y Pedagógica Universitaria. Concepción: Universidad San Sebastián; 2008.

2. Míguez M. El núcleo de una estrategia didáctica universitaria: motivación y comprensión. Revista ieRed: Revista electrónica de la Red de Investigación Educativa 2005. URL: http://revista.iered.org/v1n3/html/mmiguez.html. [04.11.2009].

3. Huertas JA. Motivación. Querer aprender. 1 ed. Buenos Aires: Aique; 1997.

4. Alonso-Tapia J. Motivar para el aprendizaje. 1 ed. Barcelona: Edebé-Don Bosco; 1997.

5. Mc Robbie C, Tobin K. A social constructivist perspective on learning environments. Int J Sci Educ 1997; 19: 193-208.

6. Durán L. La motivación, factor determinante del éxito. Breves Universidad/Comunidad Escolar 2002; 626: 28-33.

7. Universidad de Chile. Estudio final sobre causas de deserción universitaria. Informe del Centro de Microdatos del Departamento de Economía. Santiago: Universidad de Chile; 2008.

8. Parra E. Evaluación para los aprendizajes y la enseñanza. 1 ed. Santiago de Chile: Universidad Cardenal Silva Henríquez; 2008. 